Institute of $\mathbf{F}_{\text {ood and }} \mathbf{A}_{\text {gricultural }} \mathbf{S}_{\text {ciences }}$

\title{
Manual de los Reglamentos del Agua de Florida: Comisión de Caza y Pesca de Agua Dulce ${ }^{1}$
}

\author{
Michael T. Olexa, Laura Minton, Dulcy Miller, y Sarah Corbett ${ }^{2}$
}

\section{Agradecimientos}

Los autores agradecen a Richard Budell de la Oficina de Política del Agua Agrícola del Departamento de Agricultura y Servicios al Consumidor de Florida. Los autores también agradecen a David H. Hammonds, Consultor del Programa de Salud Ambiental, Oficina de Programas de Aguas de Drenaje en el Sitio, del Departamento de Salud de Florida, y a Edward A. Bettinger, Consultor del Programa de Salud Ambiental, Oficina de Programas de Agua del Departamento de Salud de Florida.

\section{Sinopsis}

La agencia de la Comisión de Agua y Pesca de Agua Dulce (CCPAD) fue creada por el Articulo IV, Sección 9 de la Constitución de Florida de 1968. El propósito de la agencia es el manejo, protección y conservación de la vida animal silvestre y vida acuática de agua dulce. Algunas de las actividades de la agencia incluye:

- mejoramiento del hábitat.

- investigación.

- inspección de proyectos de construcción y desarrollo.

1. Este es el documento EDIS FE074, una publicación del Department of Food and Resource Economics, Florida Cooperative Extension Service, Institute of Food and Agricultural Sciences, University of Florida, Gainesville, FL. Publicada Noviembre 2002. Por favor visite la página electrónica EDIS en http://edis.ifas.ufl.edu.

2. Michael T. Olexa, es profesor del Department of Food and Resource Economics, Florida Cooperative Extension Service, Institute of Food and Agricultural Sciences, University of Florida, Gainesville, FL; y miembro de Florida Bar; Presidente de Agricultural Law Committee of The Florida Bar; y Director del Agricultural Law Center. Laura Minton, Dulcy Miller, y Sarah Corbett son estudiantes graduadas de Levin College of Law, University of Florida, Gainesville, FL. Filiberto Reyes-Villanueva fue el traductor de la versión en ingles al español.

Esta publicación esta diseñada para proporcionar información precisa, actualizada y autorizada sobre esta material. Sin embargo, ya que las leyes, reglas administrativas y decisiones de la corte, sobre las cuales están basados, están sujetas a revisión constante; algunas partes de esta publicación podrían ser obsoletas en cualquier momento. Esta publicación es distribuida bajo el entendimiento que los autores no están involucrados en ninguna representación legal u otros servicios profesionales, y que la información contenida aquí no debe ser considerada como un substituto de una asesoria legal. Esta publicación no esta completa en proporcionar toda la información para lograr el cumplimiento de las leyes y reglamentos que gobiernan la protección del agua. Por estas razones, el uso de estos manuales por cualquier persona constituye un acuerdo para mantener libre de daño a los autores, al Florida Cooperative Extension Service, al Institute of Food and Agricultural Sciences, y a la University of Florida por cualquier demanda por responsabilidad de daños, o gastos en que pueda incurrir cualquier persona, como un resultado de hacer referencia o confianza sobre la información contenida en esta publicación. Esta publicación fue apoyada financieramente por el Florida Department of Agriculture and Consumer Services.

El Instituto de Alimentos y Ciencias Agrícolas es Un empleador que opera bajo Acción Afirmativa y provee Oportunidades Igualitarias, dedicado a promocionar la investigación, a información educativa y otros servicios, únicamente a los individuos e instituciones que operan baj discriminación sin considerar color, raza, sexo, edad, incapacidad u origen. Para más información sobre como obtener otras publicaciones de la extensión, comuníquese con la oficina de Servicio de Extensión de su condado. Servicio de Extensión de la Florida / Instituto de Alimentos y Ciencias Agrícolas / Universidad de la Florida / Christine Taylor Waddill, Decana. 
- desarrollo de áreas de recreación publicas.

- mantener un programa de servicio de información a la conservación.

- actualizar una lista de especies de agua dulce y terrestre amenazadas o en peligro de extinción.

El Departamento de Protección Ambiental (DPA) mantiene una lista de especies marinas de Florida y el Departamento del Interior de los estados Unidos mantiene una lista nacional (ver la sección del Acta de las Especies en Peligro de extinción ). El Acta de las Especies en Peligro de Extinción hace ilegal la matanza, daño, o destrucción de estos animales o sus nidos o sus huevos.

Aunque la CCPAD tiene jurisdicción sobre cualquier corriente de agua dulce del estado, el DPA es la agencia primariamente responsable para hacer cumplir los reglamentos del agua. Las directivas jurisdiccionales en esta área, están traslapadas, ya que muchas agencias han obtenido la autoridad para dirigir en esta materia. 